\title{
Evaluation of Intensified Colorectal Cancer Treatment Using Model Based on Delphi Method, Fuzzy Logic, and Analytical Hierarchy Process (DFAHP)
}

\author{
Chia-Lun Wu, ${ }^{1}$ Tao-Wei Ke, ${ }^{2}$ and Teen-Hang Meen ${ }^{3 *}$ \\ ${ }^{1}$ An Nan Hospital, China Medical University, 66, Sec. 2, Changhe Rd. Annan Dist., Tainan City 709, Taiwan \\ ${ }^{2}$ Department of Colorectal Surgery, China Medical University Hospital, Taichung 406040, Taiwan \\ ${ }^{3}$ Department of Electronic Engineering, National Formosa University, Huwei, Yunlin 632, Taiwan
}

(Received July 6, 2021; accepted September 9, 2021)

Keywords: colorectal cancer, medical evaluation, AHP, Delphi process, fuzzy logic theory

Colorectal cancer is one of the major fatal diseases in Taiwan, and the age of patients is decreasing yearly. As the early symptoms of malignant intestinal swelling are not obvious, most patients are not diagnosed with colorectal cancer until they are in a serious condition, and early diagnosis of colorectal cancer is a major challenge. In addition to genetic factors, colorectal cancer is caused by stress and poor dietary habits. To improve the effectiveness of treatment, we propose a model for multi-attribute decision-making based on medical data by combining the Delphi method, fuzzy logic theory, and the analytical hierarchy process. In the hierarchical structure, key risk factors and their values are proposed using fuzzy logic theory. The model suggests the importance of the medical team, medical equipment, post-operative care, and other factors for treating colorectal cancer effectively. Treatment and appropriate care must be integrated in the overall medical process to improve the effectiveness of colorectal cancer treatment.

\section{Introduction}

According to the statistics of the Health Promotion Administration, Ministry of Health and Welfare, Taiwan, cancer has been one of the ten leading causes of death since 1982. The cancer registry report in 2016 revealed that colorectal, lung, breast, liver, and oral cancer were the top five cancers in Taiwan in terms of occurrence. Among the top ten cancers in the past five years in Taiwan, colorectal cancer has been ranked first, partly due to changes in lifestyle, while it is ranked third globally. Cancer registry reports of the Health Promotion Administration revealed that the occurrence of colorectal cancer exceeded that of liver cancer and had the top annual incidence rate since 2006. About 14000 colorectal cancer cases were diagnosed in 2011, with colorectal cancer ranked first for males and second for females. The number of deaths due to colorectal cancer in the same year was about 5000, and the mortality was ranked third for males and females among all cancers. ${ }^{(1)}$

*Corresponding author: e-mail: thmeen@gs.nfu.edu.tw https://doi.org/10.18494/SAM.2021.3538 
Colorectal cancer is mainly caused by genetic problems resulting from familial inheritance and autoimmunity decline as the causes of cancers are various and difficult to specify. However, certain habits and a long-term diet of processed and fried food are also considered as causes. About $20 \%$ of colorectal cancer patients have genetic problems that cause hereditary nonpolyposis colorectal cancer (HNPCC) or Lynch syndrome and familial adenomatous polyposis (FAP). ${ }^{(2)}$ The genetic factors are generally diagnosed by tests, such as genetic screening of mismatch repair gene (MMR), adenomatous polyposis coli (APC), and MutY human homologue (MUTYH). ${ }^{(1)}$ The causes of cancer for the remaining $80 \%$ of patients are related to habits in daily life, such as diet, routine, and exercise.

The high incidence of colorectal cancer in Taiwan is partly due to the high consumption of carcinogenic foods such as processed, deep-fried, and barbecued foods. Increased toxins in the environment and increased life expectancy are also regarded as reasons. ${ }^{(3)}$ The average age of patients is decreasing, ${ }^{(4)}$ and Kaohsiung Medical University discovered a patient as young as 17 suffering from colorectal cancer in 2016. In 2013, the number of patients aged below 20 suffering from colorectal cancer was 2.1 times higher than that 10 years earlier, while the number of patients aged above 85 was 3.3 times higher. ${ }^{(5)}$

As a fecal occult blood test (FOBT) effectively screens colorectal cancer, ${ }^{(6)}$ regular health examinations contribute to the early discovery of colorectal cancer, ${ }^{(7)}$ and the immune checkpoint inhibitors should be monitored to treat metastatic colorectal cancer effectively. ${ }^{(8)}$ In terms of the seriousness of cancer cell spread, cancers are classified into stage 0 (carcinoma in situ) and stages I-IV. The conditions and treatment at various stages of colorectal cancer are shown in Table 1, and the common side effects after up to 12 sessions of chemotherapy are given in Table 2. Colorectal cancer does not show distinctive symptoms, making a specific examination necessary. ${ }^{(9)}$ Therefore, patients tend to neglect its occurrence and physicians are not able to diagnose it in its early stages. This causes a diagnostic delay due to the failure of communication between patients and physicians. ${ }^{(10)}$ When patients are diagnosed with colorectal cancer, they think that it has a low survival rate. Thus, they tend to seek cross-disciplinary medical treatments, ${ }^{(11-13)}$ complete affiliated medical care, ${ }^{(14)}$ medical care services, ${ }^{(15)}$ patient-centered medical care centers, ${ }^{(16)}$ and renowned physicians through various channels. This results in a delay in the appropriate diagnosis and treatment by physicians. Regardless of the size of the cancer, hospitals that treat cancers in Taiwan have a similar standard operation procedure that includes surgery and post-operative nursing.

Table 1

Conditions and treatment of colorectal cancer at different stages.

\begin{tabular}{lll}
\hline Stage & \multicolumn{1}{c}{ Condition } & \multicolumn{1}{c}{ Treatment } \\
\hline 0 & $\begin{array}{l}\text { Carcinoma in situ; cancer cells not spreading to } \\
\text { nearby tissues; high success rate of treatment }\end{array}$ & Remove tumors with surgery or colonoscopy \\
\hline I/II & $\begin{array}{l}\text { Early local tissue cancer; cancer cells not } \\
\text { spreading to peripheral lymph nodes }\end{array}$ & Remove tumors with surgery \\
\hline III & $\begin{array}{l}\text { Cancer cells locally spreading to lymph nodes } \\
\text { but not to other parts of the body }\end{array}$ & $\begin{array}{l}\text { 1. Remove tumors with surgery } \\
\text { 2. 12 sessions of chemotherapy as the major treatment }\end{array}$ \\
\hline IV & $\begin{array}{l}\text { Tumors have spread to other organs or parts of } \\
\text { the body }\end{array}$ & $\begin{array}{l}\text { 1. No surgery is suggested before metastasis is found } \\
\text { 2. Mainly targeted chemotherapy }\end{array}$ \\
\hline
\end{tabular}


Table 2

Common side effects after up to 12 sessions of chemotherapy.

\begin{tabular}{|c|c|c|}
\hline Chemotherapy & Side effects & Adjuvant therapy \\
\hline $1-6$ sessions & $\begin{array}{l}\text { 1. Local hair loss, vomiting, anorexia, } \\
\text { diarrhea } \\
\text { 2. Reduced mental health, increased sleep } \\
\text { time required }\end{array}$ & $\begin{array}{l}\text { 1. Granisetron }(1 \mathrm{mg} / \text { tablet), setron }(1 \mathrm{mg} / \\
\text { tablet) (vomiting) } \\
\text { 2. Megatus (oral suspension) }(40 \mathrm{mg} / \mathrm{ml}) \\
\text { (anorexia) } \\
\text { 3. Smecta: dioctahedral Smectitl }(3 \mathrm{~g}) \\
\text { (diarrhea) }\end{array}$ \\
\hline $7-12$ sessions & $\begin{array}{l}\text { 1. Local hair loss, nausea, vomiting, anorexia, } \\
\text { diarrhea } \\
\text { 2. Mental weakness, requiring longer sleep } \\
\text { time } \\
\text { 3. Tongue numbness and cavities, oral cavities } \\
\text { 4. Finger/toe end numbness }\end{array}$ & $\begin{array}{l}\text { 1. Medication as above } \\
\text { 2. Dexa Orabase } 0.1 \% \text { ( } 5 \mathrm{~g} / \text { tube), Difflam Forte } \\
\text { (throat spray, } 15 \mathrm{ml} \text { ) (tongue numbness and } \\
\text { oral cavities) } \\
\text { 3. Dipeptiven } 100 \mathrm{ml} \text { (finger/toe end } \\
\text { numbness) }\end{array}$ \\
\hline $1-12$ sessions & Stable leukocyte $(4000-10000 / \mu 1)$ & Daily supplement (zinc) \\
\hline Remarks & $\begin{array}{l}\text { Finger/toe end numbness, tongue numbness } \\
\text { and cavities, oral cavities }\end{array}$ & $\begin{array}{l}\text { 1. Chinese medicine adjuvant therapy: } \\
\text { Kanluyin, Bupleurum/Rehmannia } \\
\text { combination, bamboo leaf, Huangqin, or } \\
\text { Bletillastriata according to symptoms } \\
\text { 2. L-glutamine, sustained-release B-complex }\end{array}$ \\
\hline
\end{tabular}

During cancer treatment, communication with physicians helps patients reduce anxiety and understand their symptoms, and physicians can suggest appropriate self-treatment methods. Such communication allows early diagnosis and appropriate and effective treatment and care. Active communication and preparation for treatment also help to reduce the risk of further development of cancer. ${ }^{(17,18)}$ Early diagnostics allows laparoscopic surgery, which causes smaller incisions, from which the patients can recover faster than those resulting from traditional surgery. It also reduces patients' post-operative pain and eases aftercare. Laparoscopic cytoreductive surgery is technically feasible and safe for treating colorectal cancer patients with limited peritoneal metastases by experienced laparoscopic surgeons. ${ }^{(19)}$ Moreover, it benefits the patients and hospitals in terms of operative nursing care, ward facilities, caregiver management, visitor management, public health, patients' mental health, stable conditions, and rehabilitation effectiveness. ${ }^{(20)}$

Telemedicine has become widespread owing to the rapid development of information and communication technologies (ICTs) such as the Internet of Things. It does not have limits such as geographical barriers and is beneficial for developing countries. With the COVID-19 pandemic, the importance of telemedicine will be greater than before. Telemedicine requires new ICT products and services, in which telemedicine sensors including various wearable and implanted sensors play an important role. The information from telemedicine devices is used to devise an effective strategy for treating patients for diseases including cancer. Therefore, in preparation for the era of telemedicine and to effectively care for cancer patients, it is important to find an appropriate strategy of treatment and post-operative care. As an attempt to find such a strategy, we combine the Delphi method, fuzzy logic theory, and analytic hierarchy process (AHP) for multi-attribute decision-making into a Delphi-fuzzy logic-AHP method (DFAHP). Results obtained with the combined method can be applied to decision-making in various fields of study. 
The structure of this paper is as follows. In Sect. 2, we explain the Delphi method, AHP, and fuzzy logic theory. Section 3 describes how we use and combine the three methods into the DFAHP model proposed in this study by showing the results of each method. Section 4 concludes this study.

\section{Methodology}

\subsection{Delphi method}

The Delphi method facilitates the decisions of an expert group. It was first used to predict the future development of RAND Corporation in 1946. The Delphi method helps evaluation, decision-making, management communication, and planning for various purposes such as military science, social science, healthcare management, business, and education. ${ }^{(21)}$ The Delphi method is a decision-making technique that involves getting a group of experts to find factors related to purposes, basic assumptions, advantages, or limitations of research. Questionnaires submitted to experts in the Delphi method allow understanding and confirmation of the key factors appropriate for research ${ }^{(22)}$ by repeating and modifying questionnaire surveys until a certain consensus is reached. The survey procedure of the Delphi method of giving a questionnaire to experts is summarized as follows and shown in Fig. 1.

(1) Experts are anonymously invited but do not know that they are assisting in a questionnaire survey.

(2) The first questionnaire is designed on the basis of preliminary factors compiled from a literature review or interviews.

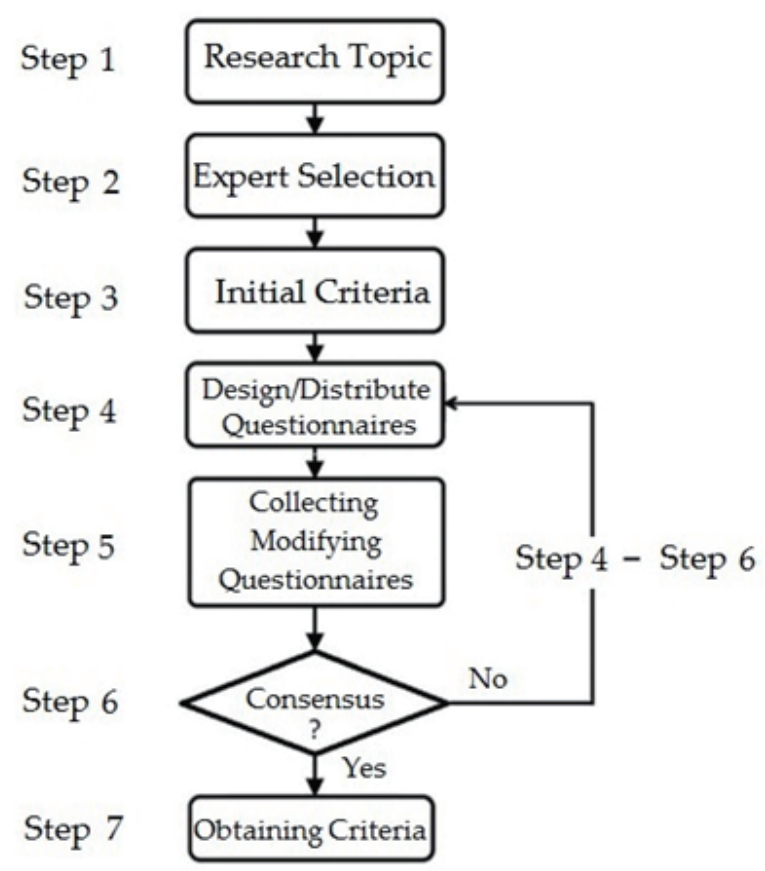

Fig. 1. Flow chart of Delphi questionnaire survey. 
(3) A questionnaire survey is conducted by interviews with experts, which are conducted separately to avoid mutual influence.

(4) The questionnaire survey data are collected and analyzed. After completing the first questionnaire survey, the survey data of the experts are analyzed to understand the opinions on the preliminary factors. If they all agree, the survey is terminated.

(5) If the results show different opinions on the influencing factors, new influencing factors are compiled. A second questionnaire is designed and carried out.

(6) The previous steps are repeated until all experts reach a consensus on the factors.

(7) The influencing factors required for the research are confirmed, and the questionnaire survey is completed.

Examples of the application of the Delphi method to medical research include research on colorectal and breast cancer, ${ }^{(23)}$ guidance in emergency nursing practice, ${ }^{(24)}$ international surgical guidance for COVID-19,(25) core criteria set for health, ${ }^{(26)}$ vulnerability of European pregnant women threatened by health risk factors such as chronic medical conditions, underlying diseases, smoking, alcohol, and so forth, ${ }^{(27)}$ and the eHealthResp online course for pharmacists and physicians. ${ }^{(28)}$

\subsection{AHP}

The AHP theory was first proposed in 1971. The AHP is used for multi-attribute decisionmaking and finding the factors influencing events under uncertain conditions. By performing a "comparative" questionnaire survey, the ranking of each influencing factor in terms of its importance is obtained after obtaining the relative weight of each factor to provide a practical reference for decision-making. Subsequently, a quantitative analysis of the influencing factors is performed. Then, decision-makers compare the weights of the influencing factors. Ranking the impact and understanding the factors of an event improve the effectiveness of decision-making and reduce the risk from it. Nine quantitative scales are defined in general for the degree of influence of each factor and for the scale for the pairwise comparison of the factors in the AHP questionnaire survey.

The AHP evaluates the advantages and disadvantages of an event by performing a complex self-judgment and systematic calculation to transform subjective influencing factors into comparable and quantitative factors, which is helpful for decision-making and improving its effectiveness. The steps in establishing an AHP evaluation model are as follows.

(1) The impact factors of the AHP evaluation model are confirmed.

(2) A hierarchical structure of each impact factor is established.

(3) An AHP pairwise comparison questionnaire is designed, created, and distributed.

(4) The data of the AHP questionnaire are analyzed by a consistency test to validate the data. The consistency index (CI) and random index (RI) are calculated to obtain the consistency ratio $(\mathrm{CR})$ as $\mathrm{CI} / \mathrm{RI}$.

(5) The relative weight value (relative importance) of each criterion is calculated.

(6) Finally, the priority of each criterion is determined. 
The AHP is widely used in various research including decision analysis in cancer therapy, ${ }^{(29)}$ transferring research into practice, ${ }^{(30)}$ selecting drugs to be selected for a chemotherapy compounding unit, ${ }^{(31)}$ determining breast cancer therapy, ${ }^{(32)}$ and application in complex chemical processes. ${ }^{(33)}$

\subsection{Fuzzy logic theory (FLT)}

Zadeh proposed FLT as a means of calculation involving vague human semantics. ${ }^{(34)}$ FLT accepts vague semantic information such as human natural language. ${ }^{(35)}$ It converts complex and inaccurate semantics into functions for quantitative analysis. FLT has the calculation function of artificial intelligence (AI). The process of establishing an FLT model involves the establishment of fuzzy sets, a membership function (MF), quantization interval values, and an inference rule base of each criterion, and then a fuzzy logic inference system (FLIS) is constructed. The inference rule of an FLIS imitates the human brain's inference function. As FLT is part of the practical and applicable methodology of AI, it has a quantified function in decision analysis. Fuzzy logic deals with inaccurate information such as the meanings of adjectives used by humans. It is used to define the parameters for quantitative inference. The definition of relevant FLIS parameters includes the following steps.

(1) Set the fuzzy set and the quantified interval values of the fuzzy set for each criterion.

(2) Decide on an MF.

(3) Establish quantitative interval values of the output fuzzy set, MF, and fuzzy set.

(4) Establish IF-THEN rules.

With the parameters defined through the above process, an FLIS can be used for inference and quantitative decision-making. The steps for the quantitative inference of an FLIS are as follows, with an FLIS architecture diagram shown in Fig. 2.

(1) Confirm the status of each criterion input.

(2) Fuzzify the input status via the FLIS.

(3) Establish rule-based inferences for the defuzzifier.

(4) Quantify output values.

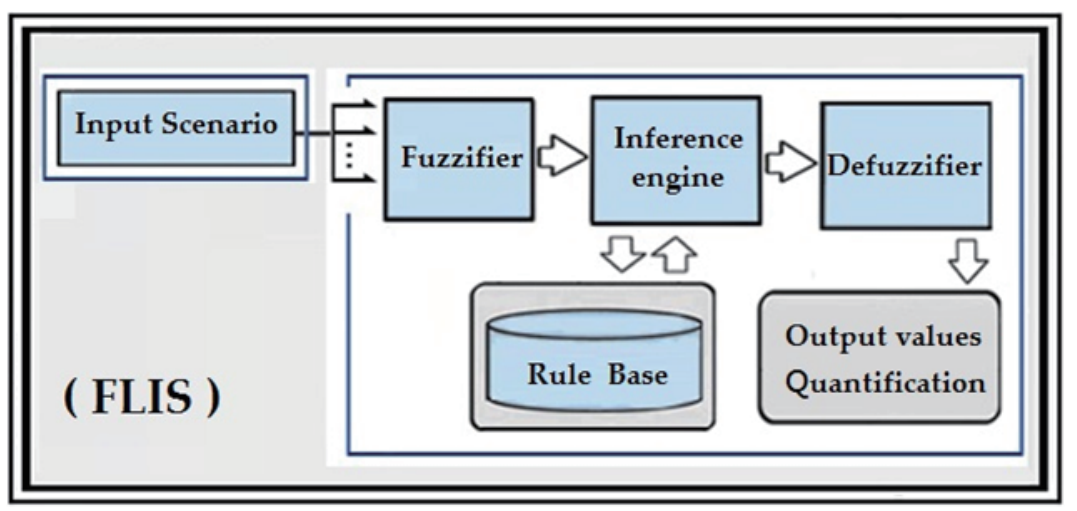

Fig. 2. (Color online) FLIS architecture diagram. 
Similarly to the AHP and Delphi, FLT is widely used in various fields. Its recent applications in the medical field and decision-related research include the forecasting of COVID-19 time series for countries, ${ }^{(36)}$ assessment of the readiness for change of healthcare organizations, ${ }^{(37)}$ infectious disease diagnosis, ${ }^{(38)}$ disease diagnosis, ${ }^{(39)}$ adaptive e-assessment, ${ }^{(40)}$ and uncertain multi-criteria decision-making problems. ${ }^{(41)}$

\section{Results and Discussion}

\subsection{Delphi method}

Four surgeons, one physician, one physician practicing in traditional Chinese medicine, three head nurses, two professional caregiver managers, and one patient (twelve people in total) were invited as experts with experience in colorectal cancer surgery and post-operative care. Thirteen preliminary factors were used as the reference for the Delphi questionnaire survey. Through the Delphi process, the experts agreed on three dimensions: the medical team, medical equipment, and post-operative care. Each dimension contained three factors.

(1) Medical team: attending physician, physician assistant, professional organization

(2) Medical equipment: advanced medical equipment, standard operation procedure (SOP), maintenance and management

(3) Post-operative care: problem feedback and solution, nurses, caregivers

The three dimensions and nine factors were used to establish the AHP hierarchies and to build the AHP questionnaire survey.

\subsection{AHP}

The AHP in this study aims to establish evaluation criteria with multiple attributes of the dimensions and factors. First, factors consistently agreed on by the Delphi method were used to establish the AHP hierarchies (Fig. 1) and construct the paired questionnaire survey. The valid questionnaire survey data were then analyzed to calculate the relative weights $\left(\omega_{i}\right)$ of dimensions and factors with the AHP. The data were validated for consistency. Ninety-two AHP questionnaires were distributed to physicians, nurses, professional caregivers, patients, and patients' families in a general hospital, and 63 valid replies were returned (response rate of 68\%). The relative weights of factors were calculated as shown in Tables 3-6. The tables show the consistency and randomness of the AHP questionnaires, which demonstrate the validity of the method. In general, $\mathrm{CI} \leq 0.1$ is regarded as appropriate for the AHP questionnaire, while $\mathrm{CR} \leq$ 0.1 demonstrates the suitability of the method $(\mathrm{CR}=\mathrm{CI} / \mathrm{RI})$. The relative weights in Table 7 and the AHP calculation of the impact factors in the colorectal cancer treatment are explained as follows.

(1) CR at Level 1-1 is 0.0816 and turns out to be an effective relative weight. CRs at Levels 2-1, $2-2$, and 2-3 are $0.0462,0.0739$, and 0.0882 , respectively, demonstrating the consistency of the AHP. 
Table 3

(Color online) Relative weights of the factors of dimensions (Level 1-1).

\begin{tabular}{lccc}
\hline Respondent & Medical team & Medical equipment & Post-operative care \\
\hline Medical team & 1 & 5 & 1 \\
Medical equipment & 0.5 & 1 & 0.5 \\
Post-operative care & 1 & 2 & 1 \\
Weighting value & 0.49 & 0.14 & 0.37 \\
\hline Remark & & $\mathrm{CI}=0.00473, \mathrm{RI}=0.58, \mathrm{CR}=0.0816$ & \\
\hline
\end{tabular}

Table 4

(Color online) Relative weights of the factors of the dimension of the medical team (Level 2-1).

\begin{tabular}{lccc}
\hline Respondent & Attending physician & Physician assistant & Professional organization \\
\hline Attending physician & 1 & 2 & 1 \\
Physician assistant & 0.5 & 1 & 1 \\
Professional organization & 1 & 1 & 1 \\
Weighting value & 0.41 & 0.26 & 0.33 \\
\hline Remark & & $\mathrm{CI}=0.0268, \mathrm{RI}=0.58, \mathrm{CR}=0.0462$ & \\
\hline
\end{tabular}

Table 5

(Color online) Relative weights of the factors of the dimension of medical equipment (Level 2-2).

\begin{tabular}{lccc}
\hline Respondent & $\begin{array}{c}\text { Advanced medical } \\
\text { equipment }\end{array}$ & SOP & $\begin{array}{c}\text { Maintenance and } \\
\text { management }\end{array}$ \\
\hline Advanced medical equipment & 1 & 1.5 & 1 \\
SOP & 0.67 & 1 & 1.6 \\
Maintenance and management & 1 & 0.625 & 1 \\
Weighting value & 0.38 & 0.34 & 0.28 \\
\hline Remark & \multicolumn{2}{cl}{$=0.0429, \mathrm{RI}=0.58, \mathrm{CR}=0.0739$} \\
\hline
\end{tabular}

Table 6

(Color online) Relative weights of the factors of the dimension of post-operative care (Level 2-3).

\begin{tabular}{lccc}
\hline A/B & $\begin{array}{c}\text { Problem feedback and } \\
\text { solution }\end{array}$ & Nurses & Caregivers \\
\hline Problem feedback and solution & 1 & 1.5 & 3.5 \\
Nurses & 0.67 & 1 & 0.889 \\
Caregivers & 0.286 & 1.125 & 1 \\
Weighting value & 0.53 & 0.26 & 0.21 \\
\hline Remark & \multicolumn{2}{c}{$\mathrm{CI}=0.512, \mathrm{RI}=0.58, \mathrm{CR}=0.0882$} &
\end{tabular}

(2) The relative weights of the three dimensions of the medical team, post-operative care, and medical equipment are $0.49,0.37$, and 0.14 , respectively.

(3) The relative weights of the nine factors at Level 2 are 0.201 for the attending physician, 0.196 for problem feedback and solution, 0.162 for the professional organization, 0.127 for the physician assistant, 0.096 for nurses, 0.078 for caregivers, 0.053 for advanced medical equipment, 0.048 for the SOP, and 0.039 for maintenance and management. 
Table 7

(Color online) Summary of the relative weights $\left(\omega_{i}\right)$ and rankings of impacts of the dimensions and factors.

\begin{tabular}{|c|c|c|c|}
\hline Level 1: $\omega_{i}$ & Level 2: $\omega_{i}$ & Level $1 \times 2: \omega_{i}$ & Ranking \\
\hline \multirow{3}{*}{$\begin{array}{l}\text { Medical team } \\
\text { (Level 1-1) } \\
0.49\end{array}$} & $\begin{array}{l}\text { Attending physician (2-1-1) } \\
0.41\end{array}$ & 0.201 & 1 \\
\hline & $\begin{array}{c}\text { Physician assistant (2-1-2) } \\
0.26\end{array}$ & 0.127 & 4 \\
\hline & $\begin{array}{c}\text { Professional organization (2-1-3) } \\
0.33 \\
\end{array}$ & 0.162 & 3 \\
\hline \multirow{3}{*}{$\begin{array}{l}\text { Medical equipment } \\
\text { (Level 1-2) } \\
0.14\end{array}$} & $\begin{array}{l}\text { Advanced medical equipment (2-2-1) } \\
0.38\end{array}$ & 0.053 & 7 \\
\hline & $\begin{array}{c}\text { SOP }(2-2-2) \\
0.34\end{array}$ & 0.048 & 8 \\
\hline & $\begin{array}{c}\text { Maintenance and management }(2-2-3) \\
0.28\end{array}$ & 0.039 & 9 \\
\hline \multirow{3}{*}{$\begin{array}{l}\text { Post-operative care } \\
\text { (Level 1-3) } \\
0.37\end{array}$} & $\begin{array}{l}\text { Problem feedback and solution (2-3-1) } \\
0.53\end{array}$ & 0.196 & 2 \\
\hline & $\begin{array}{c}\text { Nurses }(2-3-2) \\
0.26\end{array}$ & 0.096 & 5 \\
\hline & $\begin{array}{c}\text { Caregivers }(2-3-3) \\
0.21\end{array}$ & 0.078 & 6 \\
\hline
\end{tabular}

\subsection{FLT}

Fuzzy logic theory (FLT) requires fuzzy sets, membership functions (MF), fuzzy ranges, and outputs through the Delphi process, as defined below. Then, a fuzzy logic inference system (FLIS) is constructed.

(1) Fuzzy sets: The fuzzy sets have five scenarios for each factor of the medical team, medical equipment, and post-operative care.

(2) MF: In this study, three MFs are selected. The MF illustrates the degree to which a vague semantic term belongs to a quantitative quality.

(3) Fuzzy ranges: The fuzzy range of the medical team ranges between 1 and 15, indicating the number of members of the team. The medical equipment ranges between 0 and $100 \%$, indicating its sophistication. The post-operative care ranges between 0 and $100 \%$, indicating the level of care of the overall medical team.

(4) In the definition of the output value, the fuzzy set is composed of five scenarios. The MF is composed of Gauss-MF and Tri-MF. The fuzzy range is between 0 and $100 \%$.

(5) The IF-THEN rule is at the heart of FLIS smart deduction. With the definition of the rule base, the FLIS has the functions of calculation and inference.

The definition of the above fuzzy range was selected to be 1-15 for the medical team and 0-100 for medical equipment and post-operative care, which does not affect the quantitative calculation of the FLIS. The relevant parameters of the FLIS are summarized in Table 8.

After defining the parameters as shown in Table 8, the quantitative decision analysis of the FLIS is performed. The IF-THEN rules are based on the FLIS with an AI deduction function 
Table 8

Summary of definitions of FLIS-related parameters.

\begin{tabular}{|c|c|c|c|}
\hline Criteria & Fuzzy sets & Fuzzy range & Output value \\
\hline \multirow{5}{*}{ Medical team } & Very good & & \multirow{5}{*}{$0-100$} \\
\hline & Good & & \\
\hline & Average & $1-15$ & \\
\hline & Poor & & \\
\hline & Very poor & & \\
\hline \multirow{5}{*}{ Medical equipment } & Very good & & \multirow{8}{*}{$\begin{array}{c}\text { Very good } \geq 90 \\
89 \geq \text { Good } \geq 75 \\
74 \geq \text { Average } \geq 60 \\
59 \geq \text { Poor } \geq 45 \\
\text { Very poor } \leq 44\end{array}$} \\
\hline & Good & & \\
\hline & Average & $0-100$ & \\
\hline & Poor & & \\
\hline & Very poor & & \\
\hline \multirow{3}{*}{ Post-operative care } & More than sufficient & \multirow{3}{*}{$0-100$} & \\
\hline & Sufficient & & \\
\hline & Insufficient & & \\
\hline
\end{tabular}

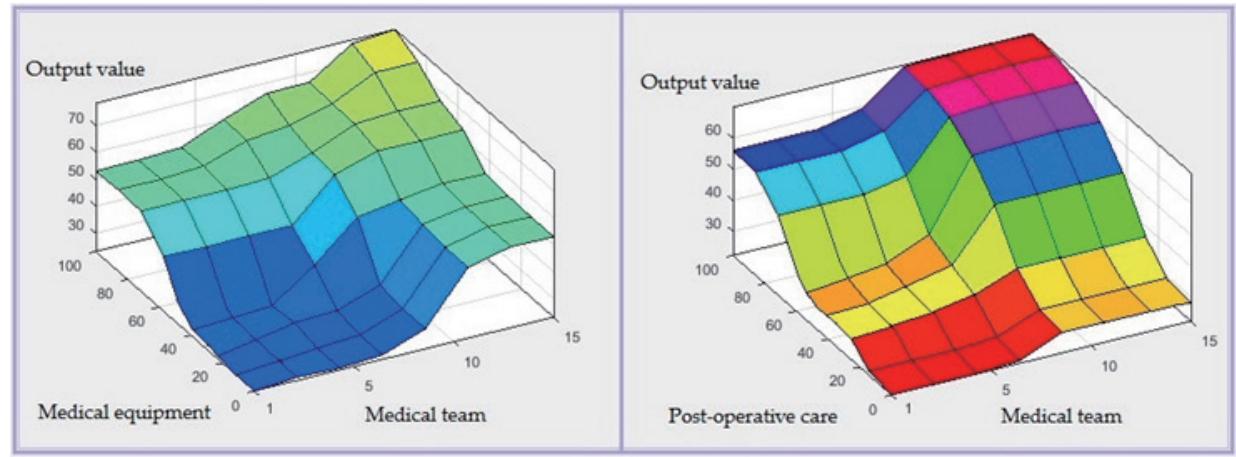

Fig. 3. (Color online) 3D mappings by FLIS according to the input scenarios.

that converts vague and uncertain adjectives into a quantitative function that provides quantitative output values. For example, a medical team with more than 12 people is considered to be appropriate, while a team with seven people is considered to be average. Then, the function decides whether nine people is a good output value. The FLIS process considers the two influencing factors of the medical equipment and post-operative care in addition to the medical team to confirm the overall quantitative output as shown in Fig. 3. Input scenarios are converted quantitatively by the FLIS, with the converted 3D mappings shown on a relationship diagram.

\subsection{DFAHP model}

A schematic diagram of the DFAHP model architecture is shown in Fig. 4. In the figure, the output value is $w_{i} \times f_{i}$ and the overall model is constructed on the basis of the Delphi process. The criteria defined by the expert group are confirmed using the model, and the level of the AHP is established by the FLIS. The AHP in the DFAHP model confirms the relative weight of each criterion, while the FLIS calculates the output value for each input scenario. The values of the criteria under various input conditions provide easy-to-compare quantitative data, which is 


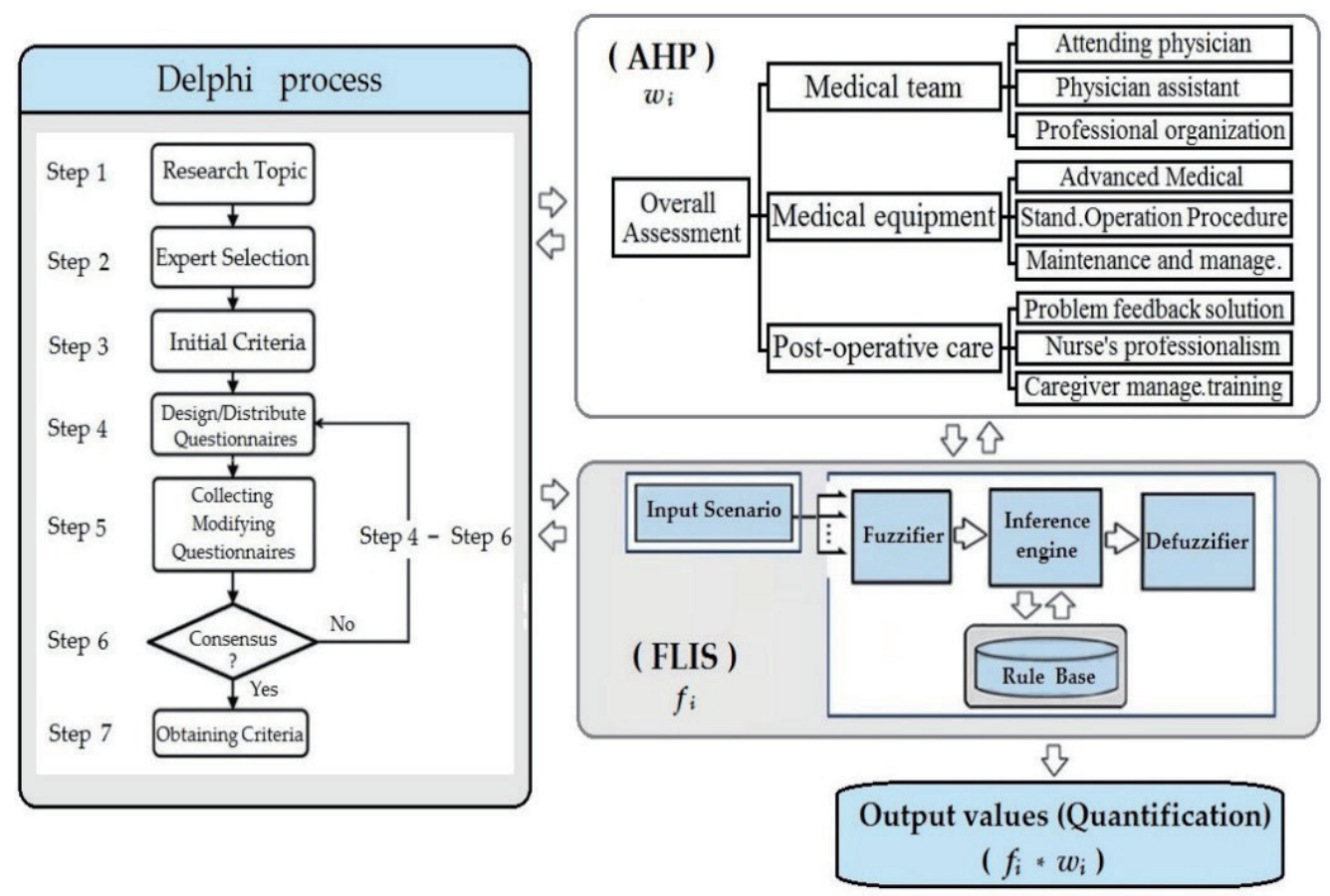

Fig. 4. (Color online) Schematic diagram of the DFAHP model architecture.

Table 9

(Color online) Three groups of ambiguous input semantics (best, average, worst) quantified using the DFAHP model.

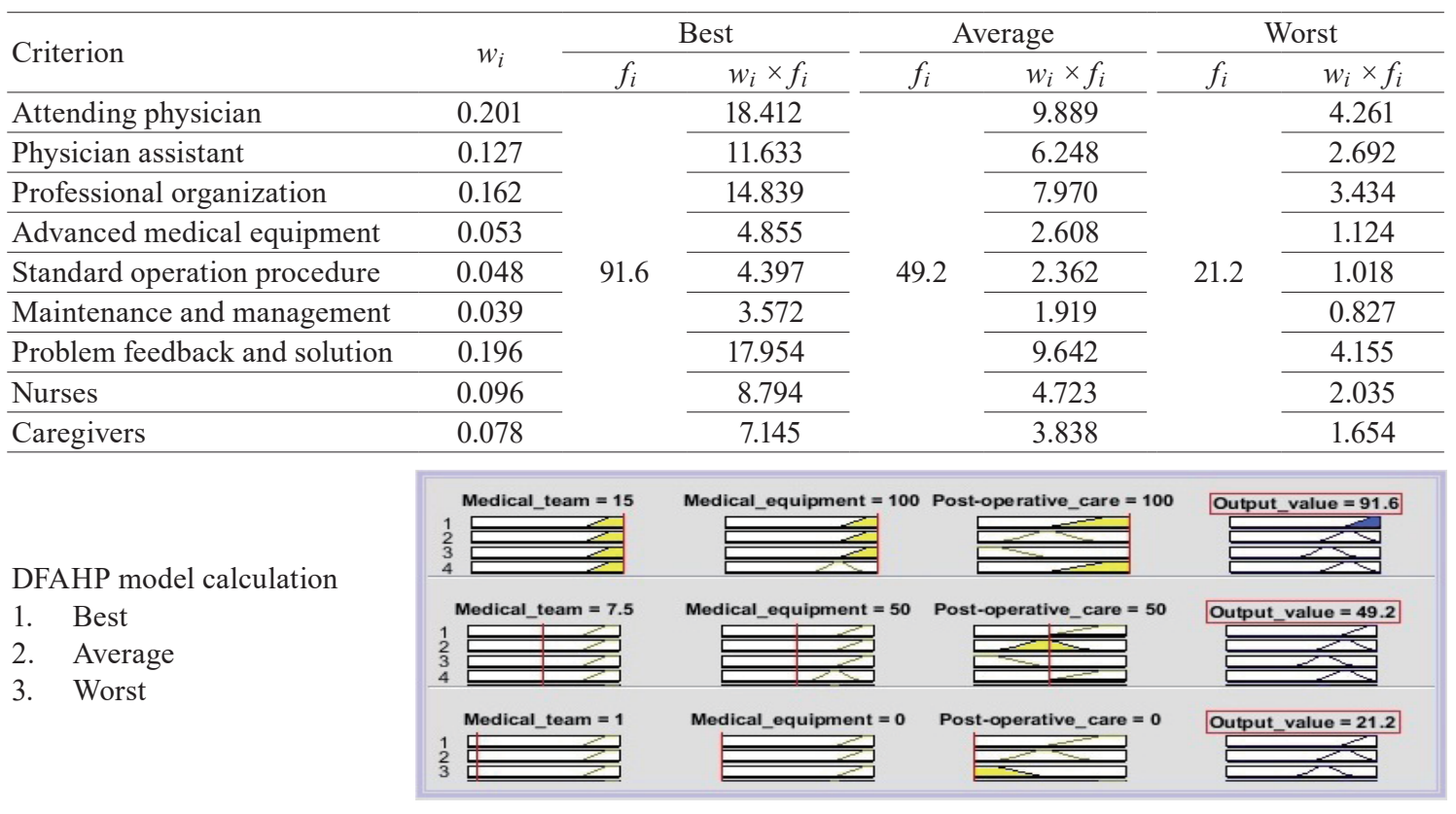

convenient for decision-making. The DFAHP model groups the calculation results as the best, average, and worst as shown in Table 9. The DFAHP model converts ambiguous inputs to specific values. 
As shown in Fig. 4, the values output by the FLIS are 91.6 as the best condition, 49.2 as the average condition, and 21.2 as the worst condition. Table 9 shows a comparison of the quantified values to illustrate the advantages and disadvantages of the situations.

\section{Conclusions}

Colorectal cancer patients and their families are faced with the physical and mental problems of communication before surgery, post-operative recovery, multiple side effects of chemotherapy, and future rehabilitation care. To solve the problems, an appropriate medical team, medical equipment, and post-operative care are required. By using the Delphi method, the FLT, and the AHP, which are combined in the DFAHP model, we confirm the criteria that affect the overall treatment of colorectal cancer and analyze the criteria for multi-attribute decision-making. The relative importances and weights of the criteria were calculated to construct an FLIS with a quantitative semantic function in the DFAHP decision-making model. The following conclusions were made from the results of the model.

(1) The DFAHP model uses an AI inference calculation that evaluates the vague semantic function. The model has qualitative and quantitative analysis functions with a high degree of objectivity, which contributes to the decision-making for appropriate medical treatment.

(2) In addition to evaluating the effectiveness of a single case, the DFAHP model evaluates the advantages and disadvantages of multiple cases at the same time. The model has the function of AI quantitative decision-making evaluation.

(3) The Delphi model confirms the three major aspects of intensive colorectal cancer treatment (medical team, medical equipment, and post-operative care) and the six key influencing factors (attending physician, problem feedback and solution, professional organization, physician's assistant, nurses, and caregivers).

(4) The trust of patients in attending physicians for colorectal cancer treatment and their care for patients during post-operative care are important as patients require psychological support after surgery.

(5) The two factors of professional organization and a physician assistant influence the habit of patients to pursue medical treatment in large hospitals and treatment by renowned doctors. Appropriate organizations and assistants avoid the problem of improper medical treatment and allow the patients to understand that the hospital can provide appropriate cancer treatment.

(6) The two factors of nurses and caregivers affect the patient's post-operative care and help improve the post-operative recovery.

(7) The DFAHP model in this study has a total of 75 different combinations. The model calculates the values of each criterion in each case. The output values of each criterion allow easy comparison, which helps managers analyze, use, and control the treatment strategy of colorectal cancer. 


\section{References}

1 Formosa Cancer Foundation: https://www.canceraway.org.tw/pagelist.asp?keyid=68 (accessed August 2021).

2 E. C. Sattler, Z. Syunyaeva, M. Reithmair, W. Dempke, and O. K. Steinlein: Eur. J. Cancer 151 (2021) 168. https://doi.org/10.1016/j.ejca.2021.04.013

3 S. E. J. Kaal, E. K. Lidington, J. B. Prins, R. Jansen, E. Manten-Horst, P. Servaes, W. T. A. van der Graaf, and O. Husson: J. Clin. Med. 10 (2021) 1833. https://doi.org/10.3390/jcm10091833

4 Liberty Times: https://health.ltn.com.tw/article/paper/1016125 (accessed August 2021).

5 Health Network: https://health.udn.com/health/story/6014/4364996 (accessed August 2021).

6 B. C. Kim, M. Kang, E. Park, J.-I. Shim, S. Kang, J. Lee, H. J. Tchoe, K. A. Kong, D. H. Kim, Y. J. Kim, K. S. Choi, and C. M. Moon: J. Clin. Med. 9 (2020) 260. https://doi.org/10.3390/jcm9010260.

7 S. M. Qaderi, H. Swartjes, and J. A. E. Custers: Eur. J. Surg. Oncol. 46 (2020) 1779. https://doi.org/10.1016/j. ejso.2020.06.017

8 G. Jung, D. Benítez-Ribas, A. Sánchez, and F. Balaguer: J. Clin. Med. 9 (2020) 3520. https://doi.org/10.3390/ jem9113520

9 N. Takahashi and M. Nakao: Health 15 (2021) 100839. https://doi.org/10.1016/j.ssmph.2021.100839

10 L. A. Siminoff, H. L. Rogers, M. D. Thomson, L. Dumenci, and H.-H. Sonja: Patient Educ. Couns. 4 (2011) 352. https://doi.org/10.1016\%2Fj.pec.2011.05.002

11 C. A. Holden, D. Poprawski, N. Singhal, E. Buckley, and T. Price: J. Geriat. Oncol. 11 (2020) 909. https://doi. org/10.1016/j.jgo.2019.11.002

12 E. P. Weledji: Eur. J. Surgical Oncol. 44 (2018) s23. httpa://doi.org/10.1016/j.ejso.2018.01.531

13 J. E. W. Walraven, I. M. E. Desar, J. J. M. Hoeven van der, K. K. H. Aben, R. H. A. Verhoeven, C. R. N. Rasch, V. E. P. P. Lemmens, and R. H. A. Verhoven: Eur. J. Cancer 12 (2019) 85. https://doi.org/10.1016/j. ejca.2019.08.007

14 C. Mittal, D. Dang, A. Dang, E. M. Stoffel, M. Ahnen, and S. Patel: Gastroenterology 152 (2017) s554. https:// doi.org/10.1016/S0016-5085(17)32010-3

15 L. Nouikh, H. Erraichi, S. Berrad, L. Amaadour, and M. Nawfel: Annals Oncol. 31 (2020) s189. https://doi. org/10.1016/j.annonc.2020.04.389

16 Y. R. Hong, Z. Xie, Z. A. G. Mainous, and J. Huo: Am. J. Prev. Med. 58 (2020) 107. https://doi.org/10.1016/j. amepre.2019.08.030

17 E. L. Amitay, T. Niedermaier, A. Gies, M. Hoffmeister, H. Michael, and H. Brenner: J. Clin. Med. 10 (2021) 2740. https://doi.org/10.3390/jcm10122740

18 C. Karthika, B. Hari, M. H. Rahman, R. Akter, A. Najda, G. M. Albadrani, A. A. Sayed, F. A. Akhtar, and M. M. Abdel-Daim: Biomed. Pharmacother. 140 (2021) 111704. https://doi.org/10.1016/j.biopha.2021.111704

19 S. H. Ha, S. Y. Park, J. S. Park, H. J. Kim, I. T. Woo, I. K. Park, J. G. Kim, B. W. Kang, S. J. Lee, W. K. Lee, and G.-S. Choi: Surgery 165 (2019) 775. https://doi.org/10.1016/j.surg.2018.09.017

20 A. Schram, V. Ferreira, E. M. Minnella, R. Awasthi, F. Carli, and C. Scheede-Bergdahl: Eur. J. Surg. Oncol. 45 (2019) 1592. https://doi.org/10.1016/j.ejso.2019.04.015

21 E. Ziglio and M. Adler: Gazing into the Oracle: The Delphi Method and its Application to Social Policy and Public Health (Jessicakingsley, London, 1996) p. 1.

22 J. W. Murry and J. H. Hammons: Rev. High. Educat. 18 (1995) 423. https://doi.org/10.1353/rhe.1995.0008

23 L. Benito, G. Binefa, C. Vidal, V. Carmen, M. Puig, I. Padrol, and M. Garcia: Collegian 24 (2017) 351. https:// doi.org/10.1016/j.colegn.2016.07.005

24 W. Varndell, M. Fry, M. Lutze, and D. Elliott: Internat. Emerg. Nurs. 56 (2021) 100867. https://doi.org/10.1016/j. ienj.2020.100867

25 A. J. Beamish, C. Brown, T. Abdelrahman, E. Ryan Harper, R. I. Harries, and R. J. Egan: Int. J. Surg. 127 (2020) 309. https://doi.org/10.1016/j.ijsu.2020.06.015

26 P. L. Santaguida, D. Oliver, A. Gilsing, L. Lamarche, L. E. Griffith, D. Mangin, J. Richardson, M. Kastner, P. Raina, and L. Dolovich: J. Clin. Epidemiol. 79 (2020) 105. https://doi.org/10.1016/j.jclinepi.2020.04.028

27 J. Scheele, H. W. Harmsen van der Vilet-Torij, E. M. Wingelaar-Loomans, and M. J. B. M. Goumans: Midwifery 86 (2020) 102708. https://doi.org/10.1016/j.midw.2020.102708

28 M. Estrela, F. Roque, T. M. Silva, M. Zapata-Cachafeiro, A. Figueiras, and M. T. Herdeiro: Biomed. Pharmacother. 140 (2021) 111739. https://doi.org/10.1016/j.biopha.2021.111739

29 C. Reibnitz and M. S. Saavedra: Val. Heal. 2 (1999) 45. https://www.ispor.org/publications/journals/value-inhealth/issue/Volume-2--Issue-1

30 J. G. Dolan: Patient Educat. Counsel. 73 (2008) 418. https://doi.org/10.1016/j.pec.2008.07.032 
31 L. A. Vidal, E. Sahin, N. Martelli, M. Berhoune, and B. Bonan: Exp. Syst. Appl. 37 (2010) 1528. https://doi. org/10.1016/j.eswa.2009.06.067

32 M. Hasan, İ. E. Büyüktahtakın, and E. Elamin: Omega 82 (2019) 83. https://doi.org/10.1016/j.omega.2017.12.005

33 Z. Geng, H. Li, Q. Zhu, and Y. Han: Energy 160 (2018) 898. https://doi.org/10.1016/j.energy.2018.07.077

34 L. A. Zadeh: IEEE Trans. Fuzzy Syst. 4 (1996) 103. https://doi.org/10.1109/91.493904

35 L. A. Zadeh: Int. J. Man-Machine Stud. 8 (1976) 249. https://doi.org/10.1016/S0020-7373(76)80001-6

36 O. Castillo and P. Melin: Chaos Solitons Fractals 140 (2020) 110242. https://doi.org/10.1016/j.chaos.2020.110242

37 V. Vaishnavi and M. Suresh: J. King Saud University-Engin. Sci. (2020) (in press). https://doi.org/10.1016/j. jksues.2020.09.008

38 G. Arji, H. Ahmadi, M. Nilashi, T. Rashid, O. H. Ahmed, N. Aljojo, and A. Zainol: Biocybern. Biomed. Eng. 39 (2019) 937. https://doi.org/10.1016/j.bbe.2019.09.004

39 H. Ahmadi, M. Gholamzadeh, L. Shahmoradi, M. Nilashi, and P. Rashvand: Comput. Methods Programs Biomed. 161 (2018) 145. https://doi.org/10.1016/j.cmpb.2018.04.013

40 K. Chrysafiadi, C. Troussas, and M. Virvou: Expert Syst. Appl. 161 (2020) 113614. https://doi.org/10.1016/j. eswa.2020.113614

41 L. Chen, G. Duan, and S. Y. Wang: Expert Syst. Appl. 149 (2020) 113303. https://doi.org/10.1016/j. eswa.2020.113303 